\title{
VITAMIN D DEFICIENCY AMONG CHILDREN WITH SEPSIS IN A TERTIARY CARE CENTER IN EASTERN NEPAL
}

Shyam Prasad Kafle, ${ }^{1}$ Eqtedar Ahmad, ${ }^{2}$ Lalan Prasad Rauniyar, ${ }^{3}$ Namu Koirala ${ }^{4}$

\begin{abstract}
INTRODUCTION

Vitamin D deficiency (VDD) is exceedingly predominant in children leading to dysregulation of the immune system and inflammation. Data on the prevalence of VDD in children with sepsis and its association with sepsis severity are limited from our part of the world. The primary aim of this study was to identify the burden of VDD in children with sepsis.
\end{abstract}

\section{MATERIAL AND METHODS}

One hundred and five children (<15 years) with sepsis were enrolled from April 15, 2017 to April 14, 2018 from a tertiary care center in Eastern Nepal. Demographic data including BMI, sequential organ failure assessment (SOFA) scores were recorded at the time of admission. Plasma 25-hydroxy vitamin D [25(OH)D] levels were measured by chemiluminescence immunoassay technique (CLIA) (MAGLUMI 25-OH Vitamin D; CLIA) within 24 hours of admission. Vitamin D concentrations of $<20 \mathrm{ng} / \mathrm{mL}(50 \mathrm{nmol} / \mathrm{L})$ were considered as deficient.

\section{RESULTS}

Out of the 105 children enrolled, the majority 74 (70.55\%) had vitamin D deficiency. Vitamin D was deficient in $77 \%$, $65 \%$, and $66 \%$ of children in 1-5, 5-10, and 10-15 years of age group respectively. Vitamin D deficiency was maximum $(80 \%)$ in underweight children. In the VDD group, $60 \%$ had severe sepsis, whereas only $32 \%$ had severe sepsis in vitamin D sufficient group with significant statistical association with sepsis severity and vitamin D deficiency.

\section{CONCLUSION}

A high burden of VDD is present in children with sepsis which was found to be associated with greater severity of illness.

\section{KEYWORDS}

Children, Sepsis, Vitamin D deficiency.

1. Department of Pediatrics and Adolescent Medicine, BPKIHS, Dharan, Nepal

2. Department of Pediatrics, All India Institute of Medical Sciences, Patna, India

3. Department of Pediatrics, Gajendra Narayan Singh Sagarmatha Zonal Hospital, Rajbiraj, Saptari, Nepal

4. Department of Nursing, Purbanchal University School of Health Sciences, Gothgaun, Morang, Nepal

DOI: https://doi.org/10.3126/jucms.v9i02.42004

For Coresspondence

Dr. Shyam Prasad Kafle

Department of Pediatrics and Adolescent Medicine

BPKIHS, Dharan,

Email:kafle.shyam11@gmail.com 


\section{INTRODUCTION}

Vitamin D deficiency (VDD) is exceedingly predominant in children leading to dysregulation of the immune system and inflammation. ${ }^{1,2}$ Vitamin D concentrations of $>20 \mathrm{ng} / \mathrm{mL}(50$ $\mathrm{nmol} / \mathrm{L}$ ) are considered as sufficient and below $50 \mathrm{nmol} / \mathrm{L}$ $(<20 \mathrm{ng} / \mathrm{mL})$ is considered as deficient. The availability of vitamin $\mathrm{D}$ in most foodstuffs is constrained, and mostly endogenous vitamin $\mathrm{D}$ is synthesized by exposure to bright sunlight. ${ }^{3,4}$ However, sun exposure, skin pigmentation, and fat retention can markedly alter vitamin D levels. Higher levels of melanin frequently lead to darker skin pigmentation, which decreases vitamin $\mathrm{D}$ synthesis. Madden $\mathrm{K}$ et al noted that race and age were related to VDD in critically ill children. Moreover, the genotype and concentration of vitamin D binding protein (DBP) can influence the half-life of 25(OH)D. ${ }^{5,6}$

Recent studies in children have demonstrated that there are grounds for vitamin $\mathrm{D}$ supplementation in septic children with VDD which could be a potential novel strategy in decreasing death by reducing the severity of illness and duration of hospital stay. ${ }^{5,78}$ Data on the prevalence of VDD in septic children in Nepal are very few. Moreover, none of the studies have assessed vitamin D status in children with sepsis as a homogenous population.

The primary aim of this study was to identify the burden of vitamin D deficiency (VDD) in children with sepsis admitted to the pediatrics department and to identify the association between VDD and the severity of illness.

\section{MATERIAL AND METHODS}

A cross-sectional prospective, observational study was done in the department of pediatrics and adolescent medicine BPKIHS, Dharan from April 15, 2017 to April 14, 2018 in children (1-15 years) admitted with the diagnosis of sepsis in pediatric wards and pediatric intensive care unit (PICU). Census sampling was used and admitted children (aged 1-15 years) with the diagnosis of sepsis were eligible for inclusion in the study. Parents of those children who refused to give consent, or were immunocompromised or with chronic renal disease, or liver disease, or conditions associated with gastrointestinal malabsorption, or who had received Vitamin D within 3 months before hospital admission were excluded.

Baseline demographic data such as age, gender, height/ length, weight, body mass index (BMI) (as defined and classified by world health organization /WHO) were recorded for each patient at the time of enrollment for the study. ${ }^{9}$ The severity of illness was measured using the sequential organ failure assessment (SOFA) score in the first 24 hours of admission to the PICU or pediatric wards. ${ }^{10}$
Serum vitamin D (25-hydroxycalciferol; (25-OH-D) level was estimated soon after the admission of the patient in the Biochemistry laboratory of the institute by chemiluminescent -immunoassay technique (MAGLUMI 25-OH Vitamin D; CLIA). Serum sample for $25(\mathrm{OH}) \mathrm{D}$ measurement was obtained as close as possible to admission usually within 24 hours.

By running internal controls with every batch of the test; the reliability of the vitamin D assay was assured. Vitamin D concentrations of $>20 \mathrm{ng} / \mathrm{mL}(50 \mathrm{nmol} / \mathrm{L})$ were considered as sufficient, between $16-20 \mathrm{ng} / \mathrm{mL}(30-50 \mathrm{nmol} / \mathrm{L})$ as insufficient, $5-15 \mathrm{ng} / \mathrm{mL}(<30 \mathrm{nmol} / \mathrm{L})$ as deficient, and $<5$ $\mathrm{ng} / \mathrm{ml}$ as severe deficiency as categorized by the American Academy of Pediatrics classification system 2008."

Sample size was calculated by considering 95\% CI and $80 \%$ power. According to the study by Satheesh et al, ${ }^{12}$ the prevalence of vitamin D deficiency among septic patient was $51 \%$, where $p=51 \%, \mathrm{q}=49 \%$, permissible error $\mathrm{l}=20 \%$ of $\mathrm{p}$ i.e. $10.2 \%$.

So, $\mathrm{n}=\left(\mathrm{z}^{2} 1-\alpha / 2 p \mathrm{q}\right) / 1^{2}$ which is $(1.96)^{2} \times 51 \times 49 /(10.2)^{2}=93$. Adding $10 \%$ for non-response, $\mathrm{n}=102$. Hence, sample size was estimated to be 102 .

Collected data were entered in Microsoft excel 2007 and converted into Statistical Package for Social Sciences 16 for Statistical analysis. For descriptive statistics percentage, mean, median, Standard deviation (SD), interquartile range (IQR) was calculated along with graphical and tabular presentation was made. For inferential statistics Chi-square was applied to find out the significant differences between the groups at $95 \%$ confidence interval $(\mathrm{CI})$ where $p \leq 0.05$.

Ethical clearance was obtained from the Institutional Review Committee (IRC) of BPKIHS prior to the initiation of the study (IRC/0868/016). Informed written consent was obtained from each of the parents before enrollment in the study.

\section{RESULTS}

Of the 265 children admitted with sepsis in the department of pediatrics and adolescent medicine; 180 were eligible for the study and only 105 participated in this study.

In this study, 45 children were below five years of age, 31 children were in the age group 6-10 years and 29 children were in the 11 to 15 -year age group accounting $42.85 \%, 29.52 \%$ and $27.63 \%$ respectively of the total study subjects.

In all the three age groups, majority had normal BMI where as $20 \%, 22.6 \%$ and $13.8 \%$ were undernourished in children under 5, 6-10 and 11 to 15 -year age group (Table 1). 
Table 1. Demographic profile of the septic children $(n=105)$

\begin{tabular}{|c|c|c|c|}
\hline \multicolumn{3}{|c|}{ Age group 1 to 5 years } & \multirow{2}{*}{$\begin{array}{c}\mathrm{n} 1=45(42.85 \%) \\
\text { Percentage }(\%)\end{array}$} \\
\hline \multirow{5}{*}{ Sex } & & Frequency & \\
\hline & Male & 23 & 51.1 \\
\hline & Female & 22 & 48.9 \\
\hline & $5^{\text {th }}-85^{\text {th }}$ & 29 & 64.4 \\
\hline & $<5^{\text {th }}$ & 9 & 20.0 \\
\hline \multirow[t]{2}{*}{ BMI (percentile) } & $85^{\text {th }}-95^{\text {th }}$ & 2 & 4.4 \\
\hline & $>95^{\text {th }}$ & 5 & 11.1 \\
\hline \multicolumn{2}{|c|}{ Age group 6 to 10 years } & & $\mathrm{n} 2=31(29.52 \%)$ \\
\hline \multirow{3}{*}{ Sex } & Male & 17 & 54.8 \\
\hline & Female & 14 & 45.2 \\
\hline & $5^{\text {th }}-85^{\text {th }}$ & 16 & 51.6 \\
\hline \multirow{3}{*}{ BMI (percentile) } & $<5^{\text {th }}$ & 7 & 22.6 \\
\hline & $85^{\text {th }}-95^{\text {th }}$ & 3 & 9.7 \\
\hline & $>95^{\text {th }}$ & 5 & 16.1 \\
\hline \multicolumn{2}{|c|}{ Age group 11 to 15 years } & & $\mathrm{n} 3=29(27.63 \%)$ \\
\hline \multirow{2}{*}{ Sex } & Male & 19 & 65.5 \\
\hline & Female & 10 & 34.5 \\
\hline \multirow{4}{*}{ BMI (percentile) } & $5^{\text {th }}-85^{\text {th }}$ & 19 & 65.5 \\
\hline & $<5^{\text {th }} \%$ & 4 & 13.8 \\
\hline & $85^{\text {th }}-95^{\text {th }}$ & 2 & 6.9 \\
\hline & $>95^{\text {th }}$ & 4 & 13.8 \\
\hline
\end{tabular}

BMI: body mass index, $\mathrm{n} 1=45, \mathrm{n} 2=31, \mathrm{n} 3=29, \mathrm{~N}=\mathrm{n} 1+\mathrm{n} 2+\mathrm{n} 3=105$

Of the 105 children enrolled, only 31 (29.5\%) had vitamin D level in normal range with mean vitamin D level being 27.5 $\pm 5.51 \mathrm{ng} / \mathrm{ml}$. Insufficient level of vitamin D was found in 40 subjects $(38.1 \%)$ with mean value being $18.3 \pm 1.34 \mathrm{ng} / \mathrm{ml}$. In the rest 34 subjects $(32.4 \%)$, vitamin D was in deficient range with mean value $12.4 \pm 2.14 \mathrm{ng} / \mathrm{ml}$. Median level of vitamin D in deficient children (74) was 15.3 (IQR:13.17- 18.12) ng /ml whereas, median level of vitamin $\mathrm{D}$ in sufficient population (31) was 25.5 (IQR: 21.9-32.10) ng/ml (Table 2).

Table 2. Vitamin D level at admission (ng/ml) $\quad \mathrm{N}=105$

\begin{tabular}{lcrrl}
\hline $\begin{array}{l}\text { Vitamin D level } \\
(\mathbf{n g} / \mathbf{m l})\end{array}$ & Frequency & $\begin{array}{l}\text { Percentage } \\
(\%)\end{array}$ & $\begin{array}{l}\text { Mean value } \\
\mathbf{1} \text { (SD }\end{array}$ & Median (IQR) \\
\hline Sufficient (21- 100) & 31 & 29.52 & $27.5 \pm 5.51$ & 25.5 (IQR: 21.9- 32.10) \\
Insufficient (16-20) & 40 & 38.10 & $18.3 \pm 1.34$ & 15.3 (IQR:13.17- 18.12) \\
Deficient (5-15) & 34 & 32.38 & $12.4 \pm 2.14$ & \\
\hline
\end{tabular}

The mean vitamin D level in the age group 1 to 5 years was $15.81 \pm 2.51 \mathrm{ng} / \mathrm{ml}$ and that in age group 6 to 10 years was $15.40 \pm 2.23 \mathrm{ng} / \mathrm{ml}$ and that in 11 to 15 years was $18.53 \pm 3.14$ ng/ml (Table 3$)$.
Table 3. Vitamin D level in age category with mean and SD value $(n=105)$

\begin{tabular}{lll}
\hline Age (years) & Frequency $(\%)$ & Mean $(\mathbf{n g} / \mathbf{m l}) \pm$ SD \\
\hline $1-5$ & $45(42.85)$ & $15.81 \pm 2.51$ \\
$6-10$ & $31(29.52)$ & $15.40 \pm 2.23$ \\
$11-15$ & $29(27.63)$ & $18.53 \pm 3.14$ \\
\hline
\end{tabular}

SD: Standard Deviation

Vitamin D was deficient $(\leq 20 \mathrm{ng} / \mathrm{dl})$ in $77 \%$ of children in one to five years of age group, whereas $65 \%$ of children had Vitamin D deficiency in 6-10 years and 66\% in 11 to 15 -year age group. None of the participants involved in the study had vitamin $\mathrm{D}<5 \mathrm{ng} / \mathrm{dl}$. By gender, $76 \%$ of males had vitamin $\mathrm{D}$ deficiency whereas only $63 \%$ of females were deficient in vitamin D. As per BMI, in normal weight category group $\left(5^{\text {th }}\right.$ $85^{\text {th }}$ percentile) nearly $65 \%$ had vitamin D deficiency, whereas in underweight category $\left(<5^{\text {th }}\right.$ percentile BMI) $80 \%$ had vitamin D deficiency.

In overweight category around $76 \%$ of them had vitamin D deficiency. In children with less severe sepsis (SOFA score $<2$ ) nearly $59 \%$ had vitamin D deficiency, whereas in the severe sepsis group (SOFA score $\geq 2$ ) $81.5 \%$ had vitamin D deficiency. In this study, respiratory system disorder as a primary cause of sepsis was found in $43 \%$ followed by GI system (41\%). CNS and genitourinary system involvement were found in $9 \%$ and $7 \%$ respectively. Those children with disorder in CNS as a primary cause of sepsis, $89 \%$ had vitamin $\mathrm{D}$ deficiency, whereas vitamin $\mathrm{D}$ was deficient in $75 \%$ of children with respiratory disorder, $67 \%$ had genitourinary disorder and $65 \%$ had GI disorder (Table 4 ).

Table 4. Vitamin D level in accordance to age group, gender, BMI, sepsis severity and System involve $(\mathrm{n}=105)$

\begin{tabular}{lllll}
\hline \multicolumn{2}{l}{ Vitamin D level (ng /ml) } & $\begin{array}{l}\text { Deficient } \\
(\mathbf{5}-15)\end{array}$ & $\begin{array}{l}\text { Insufficient } \\
(\mathbf{1 6 - 2 0})\end{array}$ & $\begin{array}{l}\text { Normal } \\
\mathbf{( 2 1 - 1 0 0 )}\end{array}$ \\
\hline \multirow{4}{*}{ Age (years) } & $1-5$ & $15(33 \%)$ & $20(44.4 \%)$ & $10(22.2 \%)$ \\
& $6-10$ & $9(29 \%)$ & $11(35.5 \%)$ & $11(35.5 \%)$ \\
& $11-15$ & $10(34.5 \%$ & $9(31 \%)$ & $10(34.4 \%)$ \\
Gender & Male & $20(33.9 \%)$ & $25(42.4 \%)$ & $14(23.7 \%)$ \\
& Female & $14(30.4 \%)$ & $15(32.6 \%)$ & $17(37 \%)$ \\
BMI & $5^{\text {th }}-85^{\text {th }}$ & $17(26.6 \%)$ & $25(39.1 \%)$ & $22(34.4 \%)$ \\
(percentile) & $<5^{\text {th }}$ & $8(40 \%)$ & $8(40 \%)$ & $4(20 \%)$ \\
& $>85^{\text {th }}$ & $9(42.9 \%)$ & $7(33.3 \%)$ & $5(23.8 \%)$ \\
SOFA Score & $<2$ & $9(17.6 \%)$ & $21(41.2 \%)$ & $21(41.2 \%)$ \\
& $\geq 2$ & $25(46.3 \%)$ & $19(35.2 \%)$ & $10(18.5 \%)$ \\
System & Respiratory & $16(35.6 \%)$ & $18(40 \%)$ & $11(24.4 \%)$ \\
Involved & CNS & $5(45.6 \%)$ & $3(33.1 \%)$ & $1(11.1 \%)$ \\
& GI & $11(25.6 \%)$ & $17(39.5 \%)$ & $15(34.9 \%)$ \\
& GU & $2(33.3 \%)$ & $233.3 \%)$ & $2(33.3 \%)$ \\
\hline
\end{tabular}


BMI: body mass index, SOFA: sequential organ failure assessment, CNS central nervous system, GI: gastro-intestinal system GU: genitourinary system

Of the 74 children with vitamin D deficiency, $60 \%$ had severe sepsis, whereas only $32 \%$ had severe sepsis in vitamin D sufficient group. The above Table depicts significant statistical association with sepsis severity and vitamin D deficiency at $p<0.05$ (Table 5).

Table 5. Association of vitamin D level with sepsis severity $(\mathbf{n}=\mathbf{1 0 5})$

\begin{tabular}{llll}
\hline Sepsis severity & Vitamin D Level (ng /ml) & & \\
(SOFA score) & Deficient (\%) & Sufficient (\%) & $p$-value \\
$<2$ & $<20$ & $(21-100)$ & \\
$\geq 2$ & $30(40.55)$ & $21(67.74)$ & $0.011^{*}$ \\
Total & $44(59.45)$ & $10(32.26)$ & \\
\hline
\end{tabular}

Chi-square test, * significant at $\mathrm{p}<0.05 \mathrm{a}$

\section{DISCUSSION}

There is a paucity of literature regarding the burden of vitamin D deficiency on pediatric sepsis especially from Nepal. Understanding of which would aid in the management and improve the outcome of the pediatrics sepsis.

In this study, most of children (42.85\%) were below five years and $20 \%$ of them were undernourished. Only $29.5 \%$ had vitamin $\mathrm{D}$ levels in the normal range. The median level of vitamin $\mathrm{D}$ in deficient children was $15.3 \mathrm{ng} / \mathrm{ml}$ whereas, in the sufficient group, it was $25.5 \mathrm{ng} / \mathrm{ml}$ which is also in the lower range of normal value. In other studies; prevalence of vitamin $\mathrm{D}$ deficiency in Indian children was found to be $40.3 \%{ }^{13,14}$ The reported prevalence of vitamin D deficiency in Spain was $29.5 \%$, in Australia was $34.5 \%$, in Canada $40.1 \%$, was and in North America was $69 \%{ }^{15,16}$ This shows that, the burden of Vitamin D deficiency is very high in our setting as compared to developed counties but is comparable to that of Indian children.

The mean vitamin D level in the age group of one to five years and 6 to 10 years was nearly equal $(15.81$ and $15.40 \mathrm{ng} / \mathrm{ml})$ whereas in 11 to 15 years, was slightly higher $(18.53 \mathrm{ng} / \mathrm{ml})$ suggesting that it was not in the sufficient level in all the age group. The highest Vitamin D deficiency was noted in the under 5 children (77\%). Hypovitaminosis D among Delhi school children (10-18 years of age), was seen in $92.6 \%$ of the low socioeconomic group and $84.9 \%$ of the upper socioeconomic group. ${ }^{17}$ In this study, vitamin D deficiency was more in overweight children $(76 \%)$ as compared to those with normal BMI $(65 \%)$ whereas, it was highest in the underweight children $(80 \%)$. More children $(81.5 \%)$ in the severe sepsis group (SOFA score $\geq 2$ ) had vitamin D deficiency than those $(59 \%)$ in the less severe group (SOFA score $<2)$ which was statistically significant. In contrary to this study, a few studies have found no such association between VDD and severity of illness ${ }^{18,19}$ whereas some others have found an inverse correlation. ${ }^{20,21}$ Involvement of respiratory and GI system as a primary cause of sepsis was found in 43 and $41 \%$ of children whereas, vitamin D deficiency was noted in 89,75 , and $67 \%$ of children with CNS, respiratory, and genitourinary system involvement respectively as a primary cause of sepsis. Of the 74 children with the vitamin D deficiency, $60 \%$ had severe sepsis, whereas only $32 \%$ had severe sepsis in vitamin D sufficient group depicting significant statistical association with sepsis severity and vitamin D deficiency. In the metaanalysis done by Xiao D et al, it was noted that the association between vitamin $\mathrm{D}$ deficiency and sepsis was significant, with an odds ratio $(\mathrm{OR})=1.13(95 \% \mathrm{CI}, 1.18$ to $1.50, p<0.05){ }^{22}$ Contrary to this in the study by Satheesh Ponnarmeni in Chandigarh, India, it was found that the prevalence of VDD in critically ill children with sepsis was high (50.8\%) but it was not associated with greater severity of illness or other clinical outcomes. ${ }^{12}$ The prevalence of VDD by different studies have noted wide variations which might be due to the differences in the studied populations, sunlight exposure, weather, dietary intake, vitamin D supplementation, genotype variation in the proteins involved in vitamin D transportation, functioning, and metabolism, different methods of measuring $25(\mathrm{OH}) \mathrm{D}$ and different cut-off values. ${ }^{23-25}$

\section{CONCLUSION}

In conclusion, this study revealed that there is a high burden of vitamin D deficiency $(70.5 \%)$ in all the age groups. Vitamin D deficiency was maximum $(80 \%)$ in underweight children though overweight had $(76 \%)$ more burden than the normal weight children (65\%). This study also showed significant statistical association between vitamin D deficiency and severity of the sepsis $(p=0.011)$. Further studies in Nepal on a larger number of septic children exploring the association of vitamin D with sepsis severity warrant urgent study.

Strength of this study include recruitment of every patient over one year period admitted to the pediatric wards and PICU fulfilling the inclusion criteria and giving consent for the study so that every subspecialty participated in the study. To minimize the influence of factors contributing to the decline of serum levels of vitamin D following admission; a prompt collection of blood samples soon after admission (within $24 \mathrm{~h}$ of admission) was ensured. The limitation of this study is the sample size which was enrolled from a single center that may not be generalized.

\section{CONFLICT OF INTEREST}

None 


\section{REFERENCES}

1. Ponnarmeni S, Angurana SK, Singhi S, Bansal A, Dayal D, Kaur R, et al. Vitamin D deficiency in critically ill children with sepsis. Paediatr Int Child Health. 2016;36(1):15-21.

2. Watkins RR, Lemonovich TL, Salata RA. An update on the association of vitamin D deficiency with common infectious diseases. Can J Physiol Pharmacol. 2015;93(5):363-8.

3. Cetinkaya M, Cekmez F, Buyukkale G, Erener-Ercan T, Demir $\mathrm{F}$, Tunc $\mathrm{T}$, et al. Lower vitamin D levels are associated with increased risk of early-onset neonatal sepsis in term infants. J Perinatol. 2015;35(1):39e45.

4. Cizmeci MN, Kanburoglu MK, Akelma AZ, Ayyildiz A, Kutukoglu I, Malli DD, et al. Cord-blood 25-hydroxyvitamin D levels and risk of early-onset neonatal sepsis: a case-control study from a tertiary care center in Turkey. Eur J Pediatr. 2015;174(6):809e15

5. Esposito S, Lelii M. Vitamin D and respiratory tract infections in childhood. BMC Infect Dis. 2015;15:487

6. Madden K, Feldman HA, Smith EM, Gordon CM, Keisling SM, Sullivan RM, et al. Vitamin D deficiency in critically ill children. Pediatrics. 2012;130(3):421-8.

7. de Haan K, Groeneveld ABJ, de Geus HRH, Egal M, Struijs A Vitamin D deficiency as a risk factor for infection, sepsis and mortality in the critically ill: systematic review and metaanalysis. Crit Care. 2014;18(6):660.

8. McNally JD, Nama N, O'Hearn K, Sampson M, Amrein K, Iliriani K, et al. Vitamin D deficiency in critically ill children: a systematic review and meta-analysis. Crit Care. 2017;21(1):287.

9. World Health Organization. Guidelines: Update on the Management of Severe Acute Malnutrition in Infants and Children. Geneva: WHO; 2013.

10. Vincent JL, de Mendonca A, Cantraine F, Moreno R, Takala J, Suter PM, et al. Use of the SOFA score to assess the incidence of organ dysfunction/failure in intensive care units: results of a multicenter, prospective study. Crit Care Med. 1998;26:1793800 .

11. Misra M, Pacaud D, Petryk A, et al. Vitamin D deficiency in children and its management: review of current knowledge and recommendations. Pediatrics. 2008;122(2):398-417.

12. Satheesh Ponnarmeni, Suresh Kumar Angurana, Sunit Singhi, Arun Bansal, Devi Dayal, Rajdeep Kaur, Ajay Patial, Savita Verma Attri. Vitamin D deficiency in critically ill children with sepsis, Paediatrics and International Child Health. 2016;36:1:15-21.

13. Marwaha RK, Tandon N, Reddy DR, et al. Vitamin D and bone mineral density status of healthy schoolchildren in northern India. Am J Clin Nutr. 2005;82:477-82.
14. Puri S, Marwaha RK, Agarwal N, et al. Vitamin D status of apparently healthy schoolgirls from two different socioeconomic strata in Delhi: relation to nutrition and lifestyle. Br J Nutr. 2008;99:876-82.

15. Rey C, S'anchez-Arango D, Lopez-Herce J, et al. Vitamin D deficiency at paediatric intensive care admission. J Pediatr. 2014;90: 135-42.

16. Madden K, Feldman HA, Smith EM, et al. Vitamin D deficiency in critically ill children. Pediatrics. 2012;130:421-8.

17. Marwaha RK, Tandon N, Reddy DR, et al. Vitamin D and bone mineral density status of healthy schoolchildren in northern India. Am J Clin Nutr. 2005;82:477-82.

18. Rey C, Sanchez-Arango D, Lopez-Herce J, Martinez-Camblor P, Garcia-Hernandez I, Prieto B, et al. Vitamin D deficiency at pediatric intensive care admission. J Pediatr (Rio J). 2014;90:135-42.

19. Ayulo M Jr, Katyal C, Agarwal C, Sweberg T, Rastogi D, Markowitz M, et al. The prevalence of vitamin D deficiency and its relationship with disease severity in an urban pediatric critical care unit. Endocr Regul. 2014;48:69-76.

20. Madden K, Feldman HA, Smith EM, Gordon CM, Keisling SM, Sullivan RM, et al. Vitamin D deficiency in critically ill children. Pediatrics. 2012;130:421-8.

21. McNally JD, Menon K, Chakraborty P, Fisher L, Williams KA, Al-Dirbashi OY, et al. The association of vitamin D status with pediatric critical illness. Pediatrics. 2012;130:429-36.

22. Xiao D, et al. Association between vitamin D status and sepsis in children: A meta-analysis of observational studies, Clinical Nutrition. Aug 2019.

23. Tiwari L, Puliyel JM. Vitamin D level in slum children of Delhi. Indian Pediatr. 2004;41:1076-7.

24. Millen AE, Bodnar LM. Vitamin D assessment in population based studies: a review of the issues. Am J Clin Nutr.2008;87:1102-5S.

25. Holick MF. Vitamin D deficiency. N Engl J Med. 2007;357:266-81. 